\title{
NUCLEATION AND CRYSTAL GROWTH OF GLASSES PRODUCED BY A GENERIC PLASMA ARC -PROCESS
}

\author{
Ma. S. Hernández-Crespo, M. Romero and J.Ma. Rincón \\ Group of Glassy and Ceramic Materials, Instituto de Ciencias de la Construcción Eduardo Torroja, \\ CSIC. C/ Serrano Galvache nº4, 28033 Madrid, Spain.
}

\begin{abstract}
The feasibility to crystallise a glass prepared by thermal plasma vitrification of hospital wastes to produce a glass-ceramic suitable to be used as a construction material was investigated by using differential thermal analysis (DTA) and X-ray diffraction (XRD). Two crystallisation exotherms in DTA were attributed to the formation of wollastonite and a crystalline phase belonging to the melilite group (gehlenite or akermanite). DTA tests have shown that the glass is not suitable for bulk crystallisation and must be converted into a glass-ceramic by using the sintering process route through a single crystallisation step at $1000 \circ \mathrm{C}$ for $10 \mathrm{~min}$.
\end{abstract}

\section{Keywords}

Nucleation, Crystallisation, Sintering, Glass-ceramics, Plasma arc vitrification, Hospital wastes

\section{Introduction}

Previous studies on vitrification of mixed medical waste, incineration ashes and radioactive wastes have shown that thermal plasma is a promising technology for their treatment ${ }^{1-3}$. In thermal plasma vitrification, the heat generated is used to treat hazardouswastes containing metals, inorganic oxides and/or organics at temperatures above $1500^{\circ} \mathrm{C}$, at which point metal containing wastes are melted and organic contaminants are thermally destroyed. The plasma vitrification yields a leach-resistant monolithic glassy slag, which is environmentally safe for landfill disposal or can be reused as glassceramic for construction materials ${ }^{4-8}$.

Glass-ceramics are crystalline materials consisting of one or more crystalline phases and a residual glassy phase. They were developed in the 1950s by controlled devitrification of glasses, giving rise to a wide variety of technological applications such as microelectronic substrates and packaging, optically transparent components, biomedical implants, catalytic supports, membranes and sensors, as well as for the matrix of composite materials ${ }^{9,10}$. Controlled devitrification is only possible for certain glass compositions and generally takes place in two stages: formation of submicroscopic nuclei, and their growth into macroscopic crystals. These two stages are called nucleation and crystal growth ${ }^{11,12}$.

The earliest glass-ceramics were produced by a conventional glass route in which a bulk glass is crystallised by a thermal treatment in the usual two-stage process. More recently, a powder-processing route, similar to that used for conventional ceramics, has been developed in which the glass is reduced to a fine powder, shaped and heated. It is during the heating that the glass particles densify by viscous flow and then nucleate and crystallise ${ }^{13}$. For glass-ceramic production via conventional glass processing, the nuclei must readily form throughout the bulk of the parent glass and surface nucleation must be avoided. Conversely, glasses showing a strong tendency for surface crystallisation may be successfully transformed into glass-ceramic by the powder processing route. Consequently, the microstructure of glass-ceramics produced by the two routes is different.

In the glass-ceramic process it is essential that the microstructure, and hence properties, are optimised. This is achieved by control of the thermal history of the parent glass, especially the heat treatment time and temperature. In this context, Time-Temperature-Transformation (TTT) diagrams are extremely useful for presenting data from the crystal growth stage; they may be used as guides for heat treatment scheduling in the processing of glass ceramics ${ }^{14}$.

On the other hand, differential thermal analysis (DTA) has widely been used for the determination of the nucleation mechanisms and optimum nucleation temperature. This consists of the determination of 
the DTA crystallisation peak temperature after isothermal thermal treatments at different nucleation temperatures. The nucleation curve for glass-forming melts has the shape of a convex curve depicting the temperature where the nucleation rate is a maximum ${ }^{15}$.

Glass-ceramics prepared by controlled devitrification of different inorganic wastes such as coal fly ashes, hydrometallurgical wastes or fly ashes from domiciliary solid waste incineration have been widely investigated ${ }^{16-25}$. However, to our knowledge, the processing of glass-ceramics by crystallisation of wastes from hospital fly ashes treated by Arc Plasma Technology (APT) has not been explored.

In this regard, this paper reports the results of a study to characterise a glass prepared by APT vitrification of hospital wastes for the production of a glass-ceramic suitable to be used as a construction material. The nucleation kinetic is evaluated by means of DTA experiments and the crystal growth is investigated by X-ray diffraction (XRD) and TTT diagrams.

\section{Materials and methods}

\subsection{Raw material}

The hospital wastes were treated in a thermal plasma reactor designed in the Technical University of Lodz (Poland). The furnace was water cooled and the transferred arc-plasma system had a maximum output power of $150 \mathrm{~kW}$. At the beginning, a single water cooled plasma torch was operating in a non transferred mode producing laminar argon plasma-jet flow. After reaching the sufficient electrical conductivity between the feed and the graphite crucible, the laminar torch was automatically switched on to transferred arc mode. The molten waste was kept at $1550^{\circ}-1600^{\circ} \mathrm{C}$ for $30 \mathrm{~min}$, and then air cooled to room temperature.

An original glass from APT vitrification of hospital wastes was supplied by the Technical University of Lodz. This vitreous glass, hereafter denoted as PG glass (Polish Glass), showed a shiny dark green colour and appeared to be homogeneous. Table I shows the chemical composition of the as-received PG glass determined by X-ray fluorescence (XRF). In addition to the oxides showed in the table, traces of $\mathrm{B}, \mathrm{Ba}, \mathrm{Cr}, \mathrm{Cu}, \mathrm{Ni}$ and $\mathrm{Zn}$ were also determined by inductively coupled plasma method (ICP).

Table I. XRF analysis (wt \%) of PG glass prepared by APT vitrification of hospital wastes

\begin{tabular}{l|r}
\hline \multicolumn{1}{c|}{ Oxide } & wt \% \\
\hline $\mathrm{SiO}_{2}$ & 52.46 \\
$\mathrm{Al}_{2} \mathrm{O}_{3}$ & 9.49 \\
$\mathrm{Fe}_{2} \mathrm{O}_{3}$ & 3.54 \\
$\mathrm{Na}_{2} \mathrm{O}$ & 5.03 \\
$\mathrm{~K}_{2} \mathrm{O}$ & 0.50 \\
$\mathrm{CaO}$ & 24.44 \\
$\mathrm{MgO}$ & 1.93 \\
$\mathrm{TiO}_{2}$ & 1.61 \\
$\mathrm{P}_{2} \mathrm{O}_{5}$ & 0.83 \\
$\mathrm{MnO}$ & 0.05 \\
$\mathrm{LOI}$ & 0.11 \\
\hline TOTAL & 99.99 \\
\hline
\end{tabular}




\subsection{Nucleation and growth of crystals \\ 2.2.1. Dynamic DTA experiments}

DTA analyses were employed to determine the glass transition temperature $\left(\mathrm{T}_{\mathrm{g}}\right)$, the crystallisation behaviour and the nucleation curve of PG glass. The tests were carried out in a SETARAM thermal analyser, Labsys model, using platinum crucibles with calcined alumina as reference, in flowing air at $100 \mathrm{~cm}^{3} / \mathrm{min}$. All DTA curves were normalised with respect to the sample weight.

To ascertain the predominant crystallisation mechanism, bulk or surface, in the devitrification of PG glass, DTA records were performed on a monolithic bulk (approximately $4 \times 2 \times 2 \mathrm{~mm}^{3}$ ), a fine powder sample $(<35 \mu \mathrm{m})$ and a powder sample without size control. For determination of the nucleation temperature, $T_{n}$, powder glass particles were heated in the DTA equipment at $50^{\circ} \mathrm{C} / \mathrm{min}$ to different nucleation temperatures in the range $700-750^{\circ} \mathrm{C}$ and held at the respective nucleation temperature for $30 \mathrm{~min}$. After nucleation treatments, the samples were post-heated without removal from the DTA apparatus until crystallisation was complete. The plot of the temperature of the exothermic crystallisation peak, $T_{c}$, versus the nucleation temperature, $T_{n}$, allows the specification of the optimum nucleation temperature from the maximum of the curve.

The activation energy, $E_{\text {act }}$, for crystallisation was also calculated from DTA data. This can be made by investigating the dependence of the temperature corresponding to the maximum of the exothermic peak, $T_{p}$, with the heating rate. The samples were crystallised at different heating rates, $\phi$, namely 5 , $15,30,40,50^{\circ} \mathrm{C} / \mathrm{min}$. The data were analysed using the Kissinger equation ${ }^{26}$.

$\ln \left(\phi / \mathrm{T}_{\mathrm{p}}^{2}\right)=-\mathrm{E}_{\mathrm{act}} / \mathrm{RT}_{\mathrm{p}}+$ constant

where $\mathrm{R}$ is the perfect gas constant $\left(\mathrm{R}=8.314 \mathrm{~J} \mathrm{~K}^{-1} \mathrm{~mol}^{-1}\right)$. The plot of $\ln \left(\phi / \mathrm{T}_{\mathrm{p}}{ }^{2}\right)$ versus $1 / \mathrm{T}_{\mathrm{p}}$ is a straight line, whose slope gives the value of $\mathrm{E} / \mathrm{R}$ allowing the calculation of the activation energy of crystallisation.

\subsubsection{Static (quenched) experiment. TTT curves and XRD phase identification}

For determining the relative growth of crystals, as well as the TTT devitrification curve, the following experiments have been conducted. Because of the dominant surface mechanism of nucleation and crystallisation showed by the PG glass, the thermal treatments have been carried out in pressed compacts $(35 \mathrm{MPa}$ ) of glass powder (particle size in the $60-200 \mu \mathrm{m}$ range). That is to say, glassceramics samples were prepared by sintering the glass compacts in air at different temperatures in the $800-1000^{\circ} \mathrm{C}$ range and a hold time of 5-60 minutes. Sometimes, the time was elongated to 240 minutes to observe the saturation of the crystallisation. After thermal treatment, the samples were quenched in air until room temperature and then grounded to a fine powder, which was used to obtain the corresponding X-ray diffractogram, in a Philips analytical diffractometer, PW 1710 series, using $\mathrm{CuK} \alpha$ radiation.

\section{Results and discussion}

\subsection{Dynamic DTA experiments}

Figure 1 shows the DTA curves of bulk and powder PG glass. It can be seen that all samples exhibit a glass transition at around $690^{\circ} \mathrm{C}$. The curve of the fine powder sample with a particle size $<35 \mu \mathrm{m}$ shows an exothermic peak at $994^{\circ} \mathrm{C}$, with a shoulder at $885^{\circ} \mathrm{C}$, following by an endothermic peak at $1180^{\circ} \mathrm{C}$ which indicates the formation of a liquid phase. The full powdered sample (without size control) also shows a similar trace, but the corresponding peaks have lower intensity than glass with particle size $<35 \mu \mathrm{m}$. Conversely, the bulk sample does not exhibit distinct crystallisation peaks. These results indicate that surface crystallisation is the prevailing mechanism for the devitrification of PG glass and hence it is not suitable for bulk crystallisation and must be converted into a glass-ceramic by using the sintering process route. 


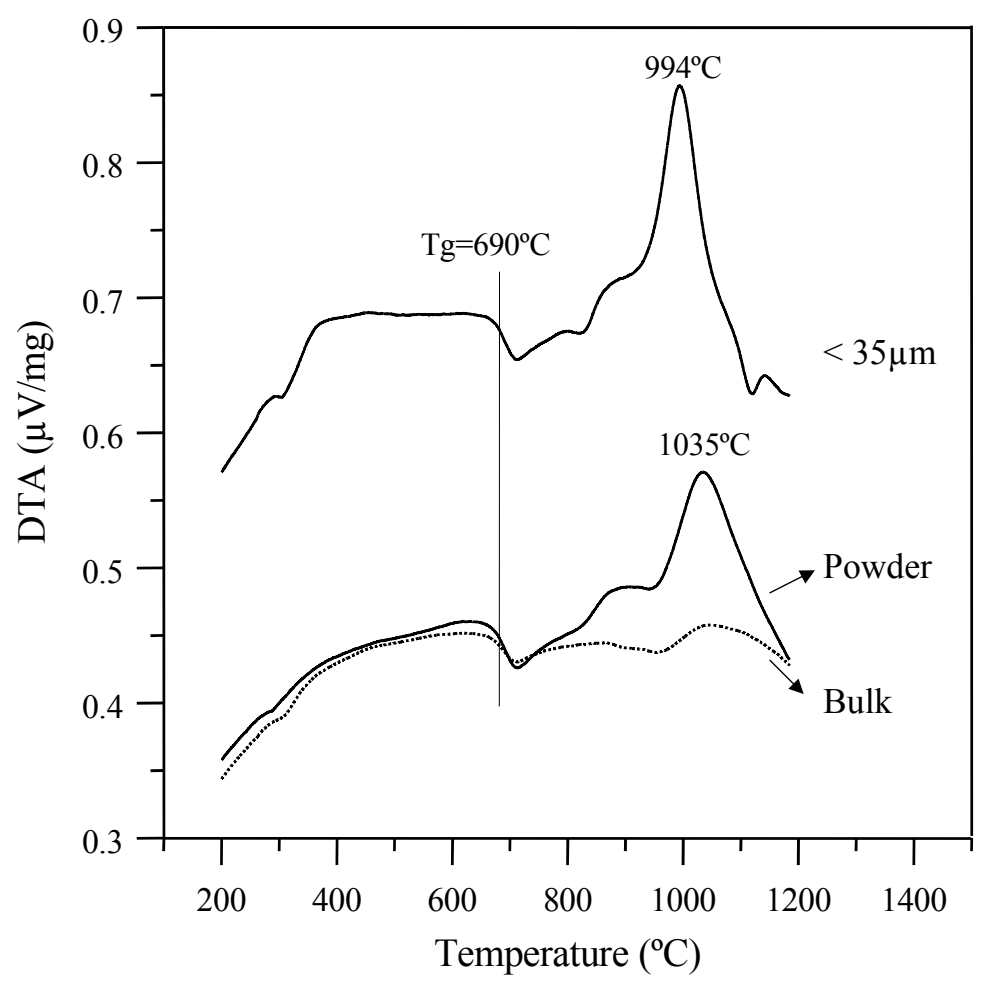

Figure 1. DTA curves of bulk and powder PG glass.

Figure 2 shows the plot of the temperature of the exothermic crystallisation peak, $T_{c}$, versus the nucleation temperature, $T_{n}$. It can be seen that there is no great differences in $T_{c}$ with $T_{n}$, which suggests that a nucleation step is not necessary for the devitrification of PG glass, which could be transformed into a glass-ceramic by a single crystallisation step.

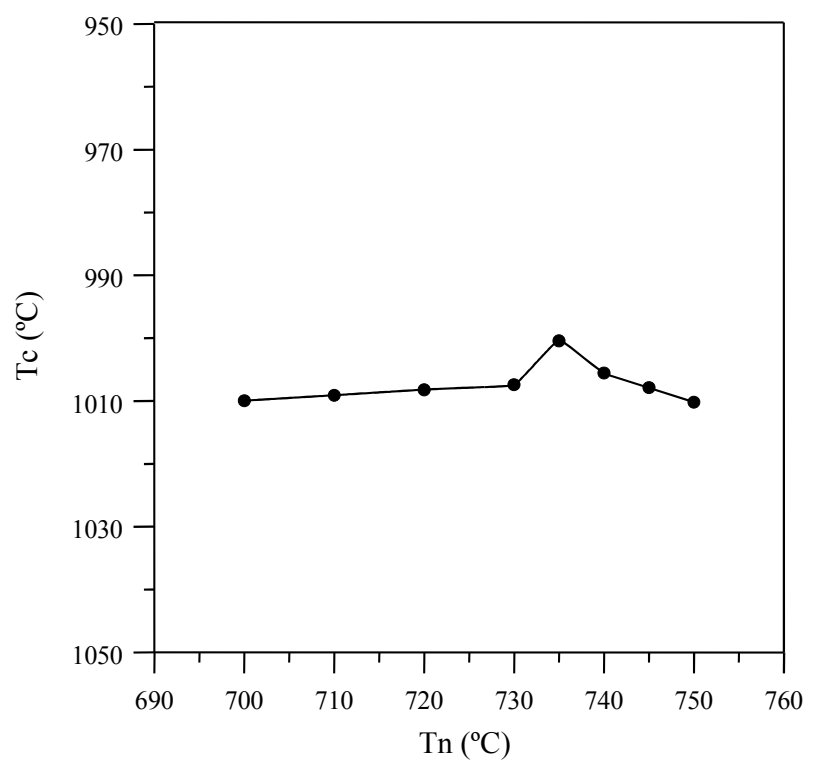

Figure 2. Plot of the temperature of the exothermic crystallisation peak, $T_{c}$, versus the nucleation temperature, $\mathrm{T}_{\mathrm{n}}$, for PG glass.

Figure 3 shows the plot of $\ln \left(\phi / \mathrm{T}_{\mathrm{p}}{ }^{2}\right)$ versus $1 / \mathrm{T}_{\mathrm{p}}$ for PG glass. As expected, a linear relationship was obtained. The value of $E_{\text {act }}$ determined from the slope of this line was $291 \mathrm{~kJ} / \mathrm{mol}$, which is lower than the value reported for glasses obtained from urban incineration ashes $(379 \mathrm{~kJ} / \mathrm{mol})$ in which surface 
crystallisation also plays a major role in the glass devitrification ${ }^{21}$. This result suggests that PG glass would be easier to crystallise than urban incineration glass perhaps owing to its chemical composition with a great content in $\mathrm{Fe}_{2} \mathrm{O}_{3}$ and $\mathrm{TiO}_{2}$, which are well established as nucleating agents for crystallisation ${ }^{11}$. The low value of $\mathrm{E}_{\text {act }}$ is in good agreement with the fact that a nucleation step is not necessary for the crystallisation of PG glass.

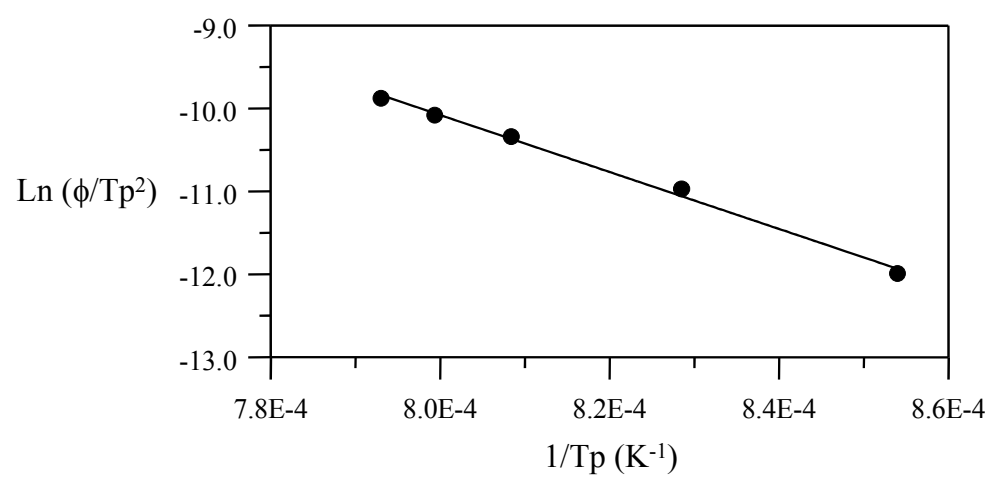

Figure 3. Plot of $\ln \left(\phi / \mathrm{T}_{\mathrm{p}}{ }^{2}\right)$ versus $1 / \mathrm{T}_{\mathrm{p}}$ for PG glass.

\subsection{Static (quenched) experiment. TTT curves and XRD phase identification}

After thermal treatment, the appearance and colour of the samples change with the temperature and time of treatment, from almost black to a wide range of brownish colours.

Figure 4 shows the TTT diagram for the crystallisation of PG glass compacts depicting a C-shaped curve, which is characteristic of nucleation and growth processes. The onset of crystallisation starts after 60 minutes of heat treatment at $800^{\circ} \mathrm{C}$, with lower treatment times as the temperature increases. Partial devitrification of the glass compacts is observed after thermal treatment at $850^{\circ} \mathrm{C}$ for 30 minutes, and the samples are fully devitrified at $850^{\circ} \mathrm{C}$ in 60 minutes. At or above $950^{\circ} \mathrm{C}$, full crystallisation is reached with a very short heating time of 5 minutes.

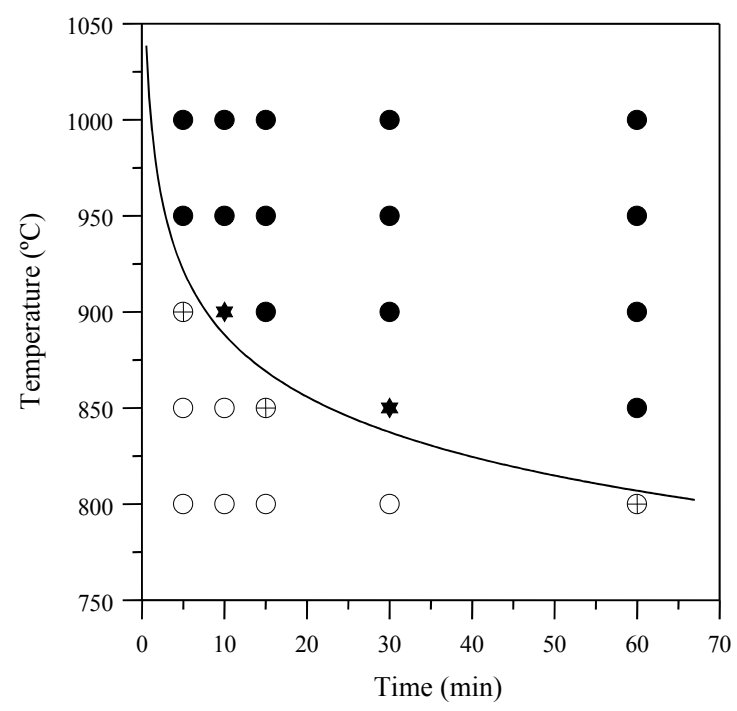

Figure 4. TTT diagram for the crystallisation of PG glass compacts ( $\bigcirc$ amorphous; $\oplus$ onset of crystallisation; $*$ partial crystallisation; 0 total crystallisation).

Figure 5 shows the X-ray diffractograms of PG glass compacts after 10 minutes of thermal treatment at different temperatures. The crystalline phases identified are gehlenite $\left(\mathrm{Ca}_{2} \mathrm{Al}_{2} \mathrm{SiO}_{7}\right)$ or akermanite $\left(\mathrm{Ca}_{2} \mathrm{MgSiO}_{7}\right)$ at lower temperatures $\left(850-950^{\circ} \mathrm{C}\right)$ and wollastonite $\left(\mathrm{CaSiO}_{3}\right)$. The Joint Committee of Powder Diffraction Standard (JCPDS) cards show that the maximum reflection at $2,85 \AA$ can be 
assigned to two members of the melilite group, gehlenite $\left(\mathrm{Ca}_{2} \mathrm{Al}_{2} \mathrm{SiO}_{7}\right)$ and akermanite $\left(\mathrm{Ca}_{2} \mathrm{MgSi}_{2} \mathrm{O}_{7}\right)$, with small deviations in the d-values. Gehlenite and akermanite have the same crystal structure and their lattice parameters are very close to each other and could give rise to solid solutions. Therefore, it is difficult to discern between both phases by only XRD analysis. Similarly, the small deviations in the d-values between monoclinic and triclinic wollastonite do not make it possible to discern the crystal system of wollastonite.

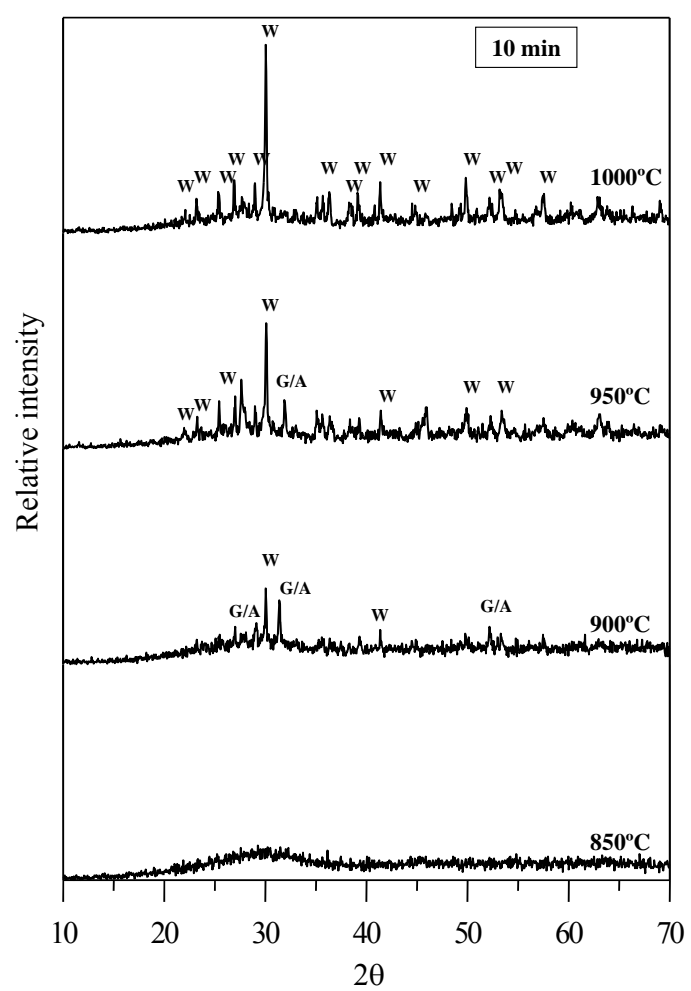

Figure 5. X-ray diffractograms of $\mathrm{PG}$ glass compacts after 10 minutes of thermal treatment at different temperatures ( $\mathrm{W}=$ wollastonite; $\mathrm{G} / \mathrm{A}=$ gehlenite/akermanite).

Figures 6 and 7 show the X-ray diffractograms of $\mathrm{PG}$ glass compacts after different heating times at 850 and $1000^{\circ} \mathrm{C}$ respectively. At $850^{\circ} \mathrm{C}$, both the intensity and the nature of the crystalline phases change with time. Thus, gehlenite/akermanite is the major phase up to $15 \mathrm{~min}$ of thermal treatment. At longer times this starts to dissolve and it is not detectable by XRD in the glass-ceramic produced after 240 minutes. As to wollastonite, it is detected after 30 minutes at $850^{\circ} \mathrm{C}$ and its intensity increases with heating time, being the only crystalline phase detectable after 240 minutes of thermal treatment. Wollastonite also is the only crystalline phase detected at $1000^{\circ} \mathrm{C}$ for different times (5-30 minutes), with its growth fully saturated after 5 minutes at this temperature. These results indicate that gehlenite/akermanite starts to crystallise at lower temperatures and shorter times than wollastonite. Thus, the lower temperature DTA exothermic (Figure 1) is due to the crystallisation of gehlenite/akermanite and the higher temperature peak is associated with wollastonite. 


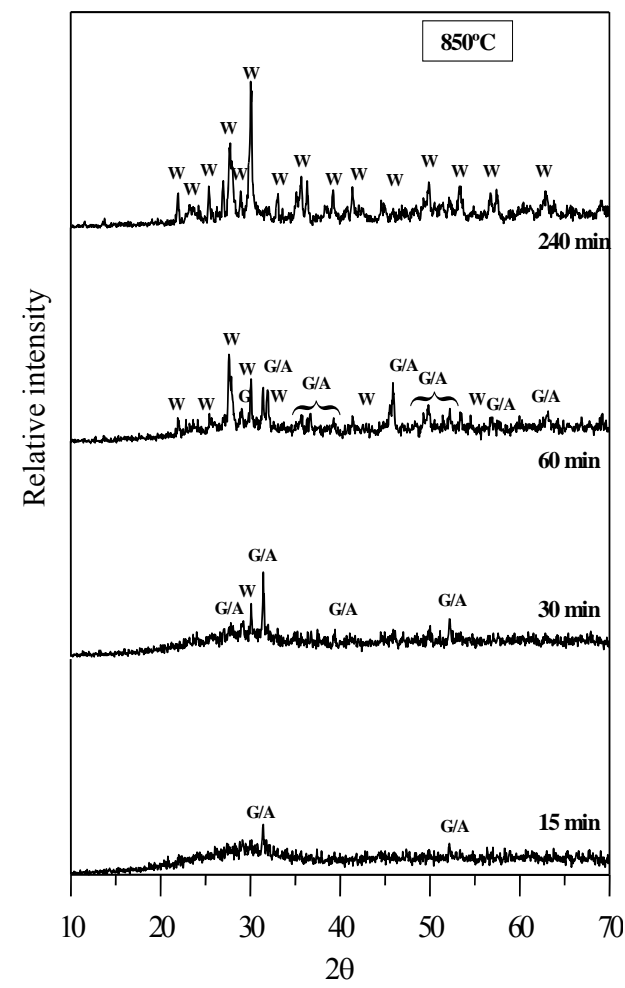

Figure 6. X-ray diffractograms of $\mathrm{PG}$ glass compacts after different heating times at $850^{\circ} \mathrm{C}$ (W=wollastonite; $\mathrm{G} / \mathrm{A}=$ gehlenite/akermanite).

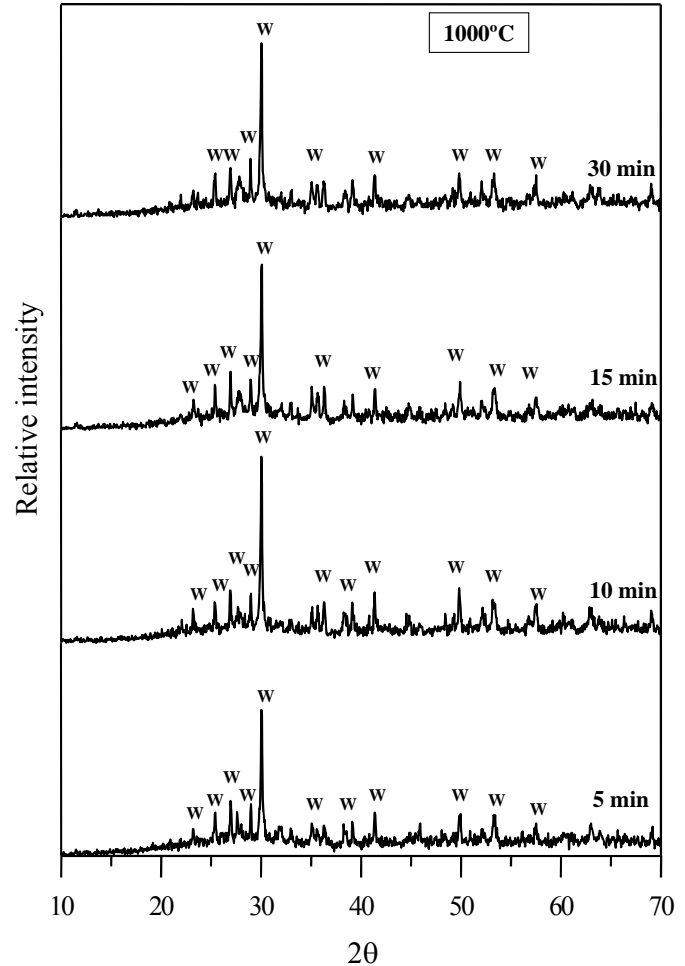

Figure 7. X-ray diffractograms of $\mathrm{PG}$ glass compacts after different heating times at $1000^{\circ} \mathrm{C}$ (W=wollastonite; $\mathrm{G} / \mathrm{A}=$ gehlenite/akermanite).

The relative proportion of wollastonite in the glass-ceramics were estimated by XRD from the ratio $I_{\text {relative }}=I_{n} / I_{\text {total }}$. The peak used for $I_{n}$ was $2,97 \AA$, which corresponds to the (-320) plane. Plots of $I_{\text {relative }}$ 
versus crystallisation temperature and time are given in Figures 8 and 9 respectively. The relative proportion of wollastonite initially increases with temperature and time and tends to saturate at lower times as the temperature increases. The higher intensity of wollastonite phase in the XRD patterns was observed in the sample heat treated at $1000^{\circ} \mathrm{C}$ for 10 minutes. Therefore, this must be considered as the optimum crystallisation treatment to transform the PG glass into a glass-ceramic material.

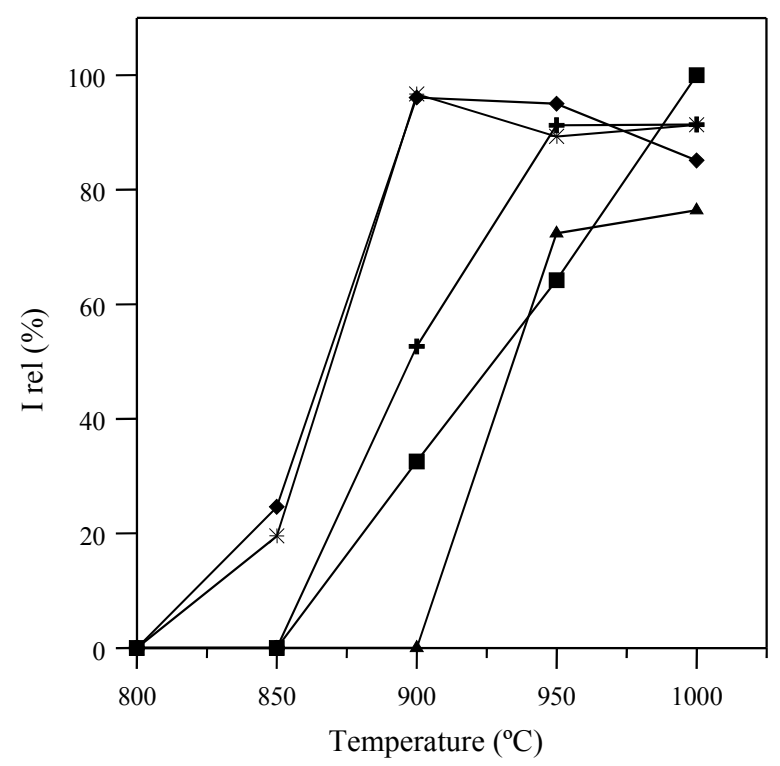

Figure 8. Plot of $\mathrm{I}_{\text {relative }}$ versus crystallisation temperature $(\boldsymbol{\Delta} 5 \mathrm{~min} ; \boldsymbol{\square} 10 \mathrm{~min} ; \boldsymbol{\$} 15 \mathrm{~min} ; \bullet 30 \mathrm{~min}$; * $60 \mathrm{~min}$ ).

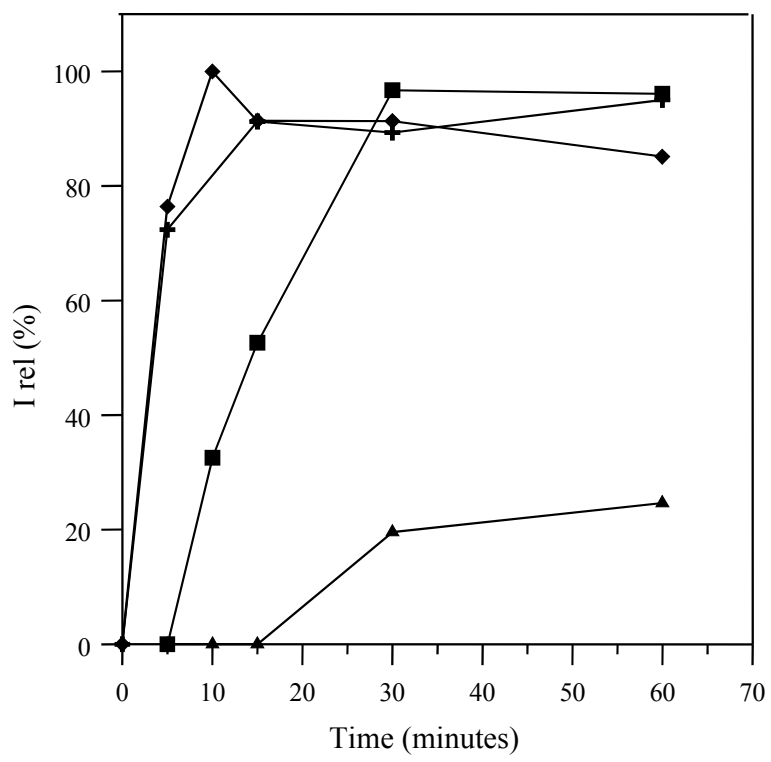

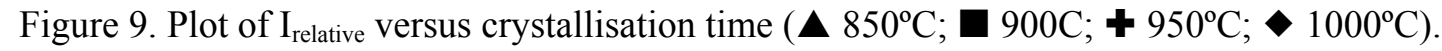

It is well known that wollastonite is a common crystalline phase in glass-ceramics formulated with high $\mathrm{CaO}$ content ${ }^{6}, 16,19$, and in conventional ceramic tiles manufactured by a fast-firing process. Wollastonite crystallisation gives high mechanical resistance to tile products and a high content of this phase in a sintered glass-ceramic will imply higher strength of the final products. Therefore, the optimum thermal treatment at $1000^{\circ} \mathrm{C}$ for 10 minutes is well suited to the industrial processing of fastfiring ceramic tiles. 


\section{CONCLUSIONS}

The powder processing route has been successfully applied to a glass prepared by thermal plasma vitrification of hospital wastes with the aim of converting it into a glass-ceramic tile suitable as a construction material. DTA analyses have shown that surface crystallisation is the prevailing mechanism for the devitrification of PG glass, which must be converted into a glass-ceramic by using the sintering process route. The value of $E_{\text {act }}$ determined by the Kissinger method was $291 \mathrm{~kJ} / \mathrm{mol}$, which is lower than the value reported for glasses obtained from urban incineration ashes $(379 \mathrm{~kJ} / \mathrm{mol})$ in which surface crystallisation also plays a major role in the glass devitrification. The low value of $\mathrm{E}_{\text {act }}$ is in good agreement with the fact that a nucleation step is not necessary for the crystallisation of PG glass. The onset of crystallisation stars after 60 minutes of heat treatment at $800^{\circ} \mathrm{C}$ and the optimum thermal treatment to transform the glass into a glass-ceramic is a treatment at $1000^{\circ} \mathrm{C}$ for 10 minutes, with wollastonite the crystalline phase devitrified.

\section{Acknowledgements}

The authors are grateful to the Economical European Community for the financial support given to this work through the GROWTH Project $n^{\circ}$ GRD1-2000-25038. The experimental assistance of Mrs. P. Díaz (IEtcc, Spain) and Mr. C. Rivera (UC-LM, Spain) is gratefully appreciated.

\section{References}

1. Chu, J.P., Hwang, I.J., Tzeng, C.C., Kuo, Y.Y. \& Yu, Y.J, Characterisation of vitrified slag from mixed medical waste surrogates treated by thermal plasma system. J.Hazard.Mater., 1998, 58, $172-$ 192.

2. Cheng, T.W., Chu, J.P., Tzeng, C.C. \& Chen, Y.S., Treatment and recycling of incinerated ash using thermal plasma technology. Waste Manage., 2002, 22, 485-490.

3. Tzeng, C.C., Kuo, Y.Y., Huang, T.F., Lin D.L. \& Yu, Y.J., Treatment of radioactive wastes by plasma incineration and vitrification for final disposal. J.Hazard.Mater., 1998, 58, 207-220.

4. Rincón, J.Ma. \& Romero, M., Glass-ceramics as Building Materials. Mater.Construcc., 1996, 46, 91-106.

5. Romero, M. \& Rincón, J.Ma., Preparation and properties or high iron oxide content glasses obtained from industrial wastes. J.Eur.Ceram.Soc., 1997, 18, 153-160.

6. Barbieri, L., Ferrari, A.N., Lancelloti, I., Leonelli, C., Rincón, J.Ma. \& Romero, M., Crystallisation of $\mathrm{Na}_{2} \mathrm{O}-\mathrm{MgO}-\mathrm{CaO}-\mathrm{Al}_{2} \mathrm{O}_{3}-\mathrm{SiO}_{2}$ glassy systems formulated from waste products. J.Amer.Ceram.Soc., 2000, 83, 2515-2520.

7. Romero, M., Rincón, J.Ma., Rawlings, R.D. \& Boccaccini, A., Use of vitrified urban incinerator waste as raw material for production of sintered glass-ceramics. Mat.Res.Bull., 2001, 36, 383-395.

8. Rincón, J.Ma., Cáceres, J., González-Oliver, C.J.R., Russo, D.O., Petkova, A. \& Hristov, H., Thermal and sintering behaviour of basalt glasses and natural basalt powders. J.Therm.Anal.Calorim., 1999, 56, 931-938.

9. Partridge, G., An overview of glass-ceramics. Part. 1. Development and principal bulk applications. Glass Technol., 1994, 35, 116-127.

10. Manfredini, T., Pellacani, G.C. \& Rincón, J.Ma., Glass-Ceramics: Fundamentals and Applications, ed. Mucchi Editore, Modena, 1997.

11. Hölland, W. \& Beall, G., Glass-ceramic Technology, The American Ceramic Society, Ohio, 2002.

12. Rincón, J.Ma., Principles of Nucleation and Controlled Crystallisation of Glasses. Polym.Plast.Technol.Eng., 1992, 3, 309-357.

13. Rincón, J.Ma. \& Romero, M., Materiales Vitrocerámicos Sinterizados. In Materiales Inorgánicos en la Construcción para el siglo XXI, Universidad Miguel Hernández and CSIC, Elche, 2001, pp. 9599.

14. Nakashima, K., Noda, K. \& Mori, K., Time-Temperature-Transformation diagrams for borosilicate glasses and preparation of chemically durable porous glasses. J.Am.Ceram.Soc., 1997, 80, 1101-1110.

15. Ray, CH.S., Ranasinghe, K.S. \& Day, D.E., Determining crystal growth rate-type of curves in glasses by differential thermal analysis. Solid State Sci., 2001, 3, 727-732. 
16. Barbieri, L., Lancelloti, I., Manfredini, T., Queralt, I., Rincón, J.Ma. \& Romero, M., Glasses and glass-ceramics from coal fly ashes. Fuel, 1999, 78, 271-276.

17. Romero, M. \& Rincón, J.Ma., Surface and bulk crystallisation of glass-ceramic in the $\mathrm{Na}_{2} \mathrm{O}-\mathrm{CaO}-$ $\mathrm{ZnO}-\mathrm{Fe}_{2} \mathrm{O}_{3}-\mathrm{FeO}_{3}-\mathrm{Al}_{2} \mathrm{O}_{3}-\mathrm{SiO}_{2}$ system derived from a goethite waste. J.Am.Ceram.Soc., 1999, 82, 1313-1317.

18. Romero, M. \& Rincón, J.Ma., The controlled vitrification/crystallisation process applied to the recycling of inorganic industrial wastes. Bol.Soc.Esp.Ceram.Vidr., 2000, 155-163.

19. Barbieri, L., Lancelloti, I., Manfredini, T., Pellacani, G.C., Rincón, J.Ma. \& Romero, M., Nucleation and crystallisation of new glasses from fly ash originated from thermal power plants. J.Am.Ceram.Soc., 2001, 84, 1851-1858.

20. Gao, Z. \& Drummond, G.H., Thermal analysis of nucleation and growth of crystalline phases in vitrified industrial waste. J.Am.Ceram.Soc., 1999, 18, 561-565.

21. Romero, M., Rawlings, R.D. \& Rincón, J. Ma., Development of new glass-ceramics by means of vitrification and crystallisation of inorganic wastes from urban incineration. J.Eur.Ceram.Soc., 1999, 19, 2049-2058.

22. Romero, M., Rawlings, R.D. \& Rincón, J. Ma., Crystal nucleation and growth in glasses from inorganic wastes from urban incineration. J.Non-Cryst.Solids, 2000, 271, 106-118.

23. Francis, A.A., Conversion of blast furnace slag into new glass-ceramic material. J.Eur.Ceram.Soc., 2004, 24, 2819-2824.

24. Francis, A.A., Rawlings, R.D., Sweeney, R. \& Boccaccini, A.R., Crystallisation kinetic of glass particles prepared from a mixture of coal ash and soda-lime cullet glass. J.Non-Cryst.Solids, 2004, 333, 187-193.

25. Cheng, T.W. \& Chen, Y.S., Characterisation of glass ceramics made from incinerator fly ash. Ceram.Int., 2004, 30, 343-349.

26. Kissinger, H.E., Variation of peak temperature with heating rate in differential thermal analysis. J.Res.Natl.Stand. (US), 1956, 57 (4), 217-221. 